\title{
DEVELOPMENT OF HETEROGENEITY INDEX FOR ASSESSMENT OF RELATIONSHIP BETWEEN LAND USE PATTERN AND TRAFFIC CONGESTION
}

\author{
Alok Bhushan Mukherjee ${ }^{1}$, Nilanchal Patel ${ }^{2}$, Akhouri Pramod Krishna ${ }^{3}$ \\ ${ }^{1,2,3}$ Department of Remote Sensing, Birla Institute of Technology Mesra, Ranchi, Jharkhand - 835215, India
}

Received 4 April 2014; accepted 25 July 2014

\begin{abstract}
The present study was carried out to determine the effects of the heterogeneity in land use distribution pattern on the traffic congestion in rapidly urbanizing Ranchi city, capital of Jharkhand state, India. Traditionally, researchers have used the landscape metrics to determine the heterogeneity in the land use and land cover distribution pattern in both urban and non-urban areas. In the present study, we have introduced a new index: Heterogeneity Index to quantify the distribution pattern of the land use categories present along the various road segments whereas traffic congestion was determined through the Congestion Index Value. Based on the dominant land use categories existing in the study area, four heterogeneity indices were developed such as Residential Heterogeneity Index, Commercial Heterogeneity Index, Industrial Heterogeneity Index and Urban Services Heterogeneity Index, respectively. Finally, a Cumulative Heterogeneity Index was developed to determine the aggregate effect of the heterogeneity of the various land use categories present in the individual roads. Analytical Hierarchical Processing and knowledge-based weighting were used to rank the importance of different heterogeneity indices. The results of the investigation showed positive relationship between the degree of heterogeneity of the land use pattern and traffic congestion.
\end{abstract}

Keywords: Analytical Hierarchical Processing, knowledge based weighting, landscape metrics, urbanization.

\section{Introduction}

Countries across globe are witnessing urbanization although the intensity may differ according to socio-political conditions of respective countries. It is a general perception that urbanization refers to increased urban density and activities at the centre of city (Ojima and Hogan, 2009). The term 'urban sprawl' was coined by William Whyte in 1958 and was defined as "expansion of an urban centre in the form of scattered development comprising different types of land use and with time, the vacant spaces between different land uses filled up with different kinds of urban activities" (Rahman et al., 2008). Urbanization is an indicator of economic growth; however the negative consequences of urban expansion on different section of society cannot be denied. The most primary and significant negative consequence of uncontrolled urbanization is rapid transformation in the land use pattern of an urban region (Cheng, 2003). The research investigations pertaining to urban planning covers a wide range of

${ }^{2}$ Corresponding author: npatel@bitmesra.ac.in 
topics spanning from urban planning, urban transportation, design and architecture, economics, geography, sociology, water and waste management and engineering (Zavrl and Zeren, 2010).

Hitherto, numerous research investigations have been carried out pertaining to urban system (Shen et al., 2013; Blanco and Giuliano, 2011; Yang, 2010; Ojima and Hogan, 2009). Urban expansion is now regarded as a global phenomenon; cities of all sizes across the world are witnessing rapid urbanization. Efficient and effective planning needs information related to pattern, process and growth of urban centers (Sudhira et al., 2004). In the $21^{\text {st }}$ century, cities have significant role in handling the challenges of globalization, sustainability and cohesion. Therefore, the emergence of new urban centers and expansion of urban areas is quite understandable. The urban expansion phenomena is associated with three major drawbacks, i.e. urban expansion causes transformation of open spaces into urban structures, increasing number of automobiles causing traffic congestion and racial segregation (Geshkov, 2010). The direct impact of urbanization can be observed on the pattern of land use. There are rapid changes in the structure of land use with the influx of migrants, industrial growth, population growth etc.

Li and Wu (2004) highlighted some significant issues, i.e. theoretical flaws in landscape pattern analysis, limitations of landscape indices and inappropriate use of pattern indices pertaining to the landscape analysis. It was emphasized that the quantitative description of landscape is not enough to understand the relationship between pattern and process and therefore, the qualitative perspective needs to be considered. Chari et al. (2011) in their study attempted to assess the impact of urbanization on changing land use pattern. They found that the agricultural land is more affected by the uncontrolled urban expansion. Since agriculture is also dependent on the groundwater and the demand of groundwater is increasing with urbanization, the rising demand of groundwater has negative consequences over the agricultural land of the study area. Williams (2010) highlighted the challenges confronting various researchers working on a vision of sustainable city development. The author emphasized that understanding of the relationship between social and technical solutions is necessary to provide real solutions for the sustainable development.

There exists close relationship between land use pattern and traffic congestion (Indian Road Congress, 1990). Due to the dynamic characteristics of congestion its definition varies according to the context and situation. The two parameters that characterize congestion are delays and lower travel speeds. Zito et al. (1999) consider congestion as the queued vehicle that invariably leads to the blockage of roads. This observation is further supported by another studies done by Lee et al. (2008) and Boamah (2010) who attributed congestion to the decrease in speed, the increase in travel time and the increase of vehicle's queue on the road. The relationship between land use and traffic flow was advocated by Srinivasan (2000). In addition, traffic congestion and its behavior depend upon the condition on the roads. Even a small change in land use pattern affects the transportation system and therefore, the pattern of land use should be considered in any kind of modelling pertaining to transportation system. Therefore, travel behavior can be 
controlled if the relationship between land use pattern and transportation is understood and monitored.

There are different techniques available to determine the status of traffic congestion such as $V / C$ ratio technique (Narayanan et al., 2003), where $V$ is traffic volume and $C$ is traffic capacity and Congestion Index Value (CIV) computed using the formula $\left(\mathrm{C}-\mathrm{C}_{0}\right) /$ $C_{0}$, where $C$ is total travel time and $C_{0}$ is the free flow time (Taylor, 1992). If $V / C$ ratio is greater than 1 , then the route is considered as congested. In case of CIV, if the value of $\left(C-C_{0}\right) / C_{0}$ is near zero it will indicate very low levels of congestion while an index greater than two generally will correspond to congested conditions. Li and Tsukaguchi (2005) proposed a new approach to analyze the topology of real existing network through which it was possible to determine the relationship between the OriginDestination pairs and network topologies. Network topology, i.e. the topology of the start point and the destination influences the pedestrian route choice behavior. The relationship between the stock market dynamics with pedestrian dynamics was studied by Godescu and Zurich (2010). Thuy (2003) employed system dynamic approach to study the urban transportation situation in Hanoi, Vietnam and determined the causes and effects of traffic congestion. Hua et al. (2013) attempted to assess the source and reasons of increasing traffic congestion in the city Beijing. It was observed that the rise of China as the leading economical and political power in the international arena made the Beijing city a global centre. Consequently, the number of motor vehicles owner in the city increased dramatically. Lee et al. (2008) emphasized that road merges are one of the most important reasons of traffic congestion. Therefore, in their investigation, a dynamic traffic simulation tool was developed using fluid dynamic algorithm to project traffic congestion on the basis of different parameters. Lindsey and Verhoef (2000) discussed the importance of economic principles in implementing congestion pricing in different urban settings, i.e. urban and rural. There are several complications that subsist in the implementation of congestion pricing such as heterogeneity in the travel pattern of users, relationship of transport and the economy etc.

The rising demand from different sectors of an urban system brings about a series of effects in sequel such as the change in the shape of urban landscape characterized by the cropping up of new built ups, decreasing open spaces etc. followed by the change in the pattern of traffic flow that could also lead to traffic congestion in favorable conditions. Traditionally researchers have used the landscape metrics to determine the pattern and structure of urban features. In order to establish link between the pattern of spatial features and traffic congestion, it is imperative to carry out empirical observations of the heterogeneity in the pattern of spatial features and assign some suitable index value based on the pattern of occurrence of the features.

In the present research, we have determined the spatial heterogeneity of the patterns of the features through heterogeneity indices developed for the different dominant land use patterns existing in the study area such as Residential Heterogeneity Index (RHI), Commercial Heterogeneity Index (CHI), Industrial Heterogeneity Index (IHI) and Urban Services Heterogeneity Index (USHI), respectively. Finally, a Cumulative Heterogeneity Index (CUHI) was developed to represent the aggregate 
effect of the various dominant land use types. Subsequently, we attempted to establish the linkage between the different heterogeneity indices and traffic flow behavior. The standard Analytical Hierarchical Processing (AHP) and knowledge-based weighting techniques were used to rank the importance of the different heterogeneity indices in the study area and in different road segments. The study was performed in the rapidly urbanizing Ranchi city, capital of Jharkhand state, India.

\section{Materials and Methods}

\subsection{Study Area}

The present research investigation was carried out in the Ranchi city, the capital of Jharkhand state, India covered in the Survey of India topo sheet No. 73 E/7 and is bounded by the spatial extension $23^{\circ} 24^{\prime}$ $06^{\prime \prime} \mathrm{N}$ to $23^{\circ} 25^{\prime} 47^{\prime \prime} \mathrm{N}$ and $85^{\circ} 26^{\prime} 57^{\prime \prime} \mathrm{E}$ to $85^{\circ} 27^{\prime} 26^{\prime \prime} \mathrm{E}$. The study area is shown in Fig. 1. The Ranchi Municipal area covers a total area of $172.7 \mathrm{~km}^{2}$. The Ranchi city has been witnessing rapid urbanization for last few years, especially after being the capital of the Jharkhand state in year 2000. Since the year of formation of the Ranchi city as the capital of the Jharkhand state, the city has witnessed huge infrastructural establishments such as a number of new commercial complexes, establishment of sports mega complex (Birsa Munda Athletics Stadium Mega Sports Complex), National hockey and football stadium (Astroturf Hockey Stadium, Morhabadi and Birsa Munda Football Stadium, Morhabadi) and International cricket stadium (JSCA International Cricket Stadium). Moreover, a few national level premier institutions and universities: Indian Institute of Management (IIM), Ranchi, Central University of Jharkhand and National Law University were established in the last few years. These developments attracted huge influx of people from outside to the city with the expectation of better employment opportunities and living standard. However, these developments also brought about negative consequences in the structural and functional characteristics of the city. There has been huge increase in the number of vehicles in the city. For instance, $67 \%$ increase in the number of vehicles was observed in the period of five years between 2004 and 2009 (Department of Transport, Jharkhand). Consequently, there is significant rise in traffic congestion across the city. Absence of adequate infrastructure in the city to meet the various challenges of increasing urbanization worsens different functional activities of the city. The random movement of vehicles and people is ubiquitous. The land use pattern along different routes of the city is heterogeneous. In a single patch, presence of different land use classes can be observed that leads to the occurrence of erratic traffic flow throughout the city. In Ranchi city, the road network has tree like structure. The route segments are generally shorter and street pattern is irregular. In general it is the mixed traffic condition that prevails throughout the city. There is a need to carry out scientific study to assess the traffic pattern in relation to the distribution of the various land use categories present along the road segments. 


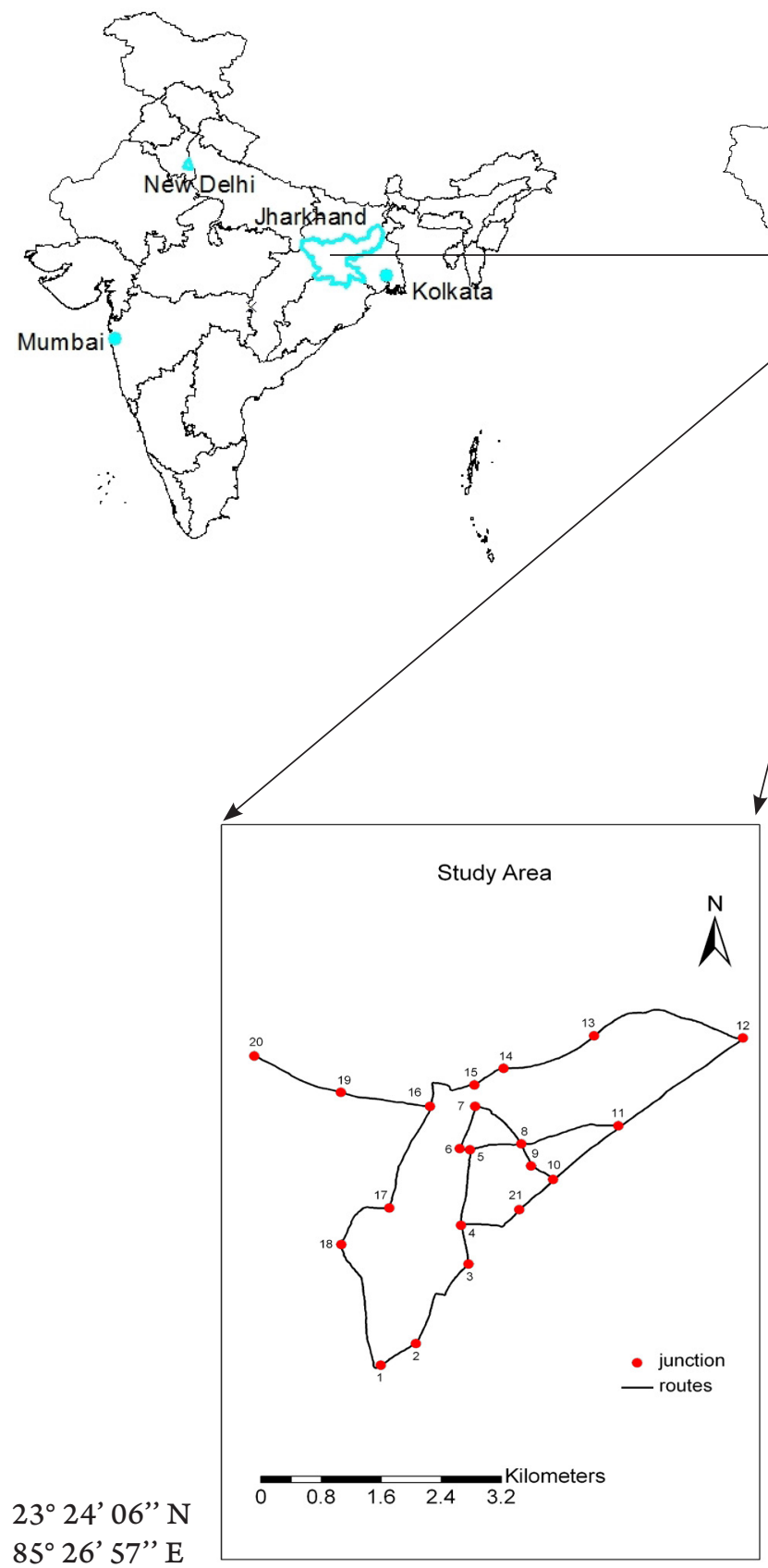

$23^{\circ} 25^{\prime} 47^{\prime \prime} \mathrm{N}$

$85^{\circ} 27^{\prime} 26^{\prime \prime} \mathrm{E}$

1. Birsa Chowk

2. Hinoo Chowk

3. Rajendra Chowk

4. Sujata Chowk

5. Firayalal Chowk

6. Saheed Chowk

7. Kutchary Chowk

8. Lalpur Chowk

9. Dangratoli Chowk

10. Kantatoli Chowk

11. Kokar Chowk

12. Booty More

13. Bariyatu

14. Karam Toli

15. Sainik Theatre

16. Ratu Chowk

17. Sahajanand Chowk

18. Argora Chowk

19. Piska More

Fig. 1.

20. Pandra

Study Area

21. Bahoo bazaar 


\subsection{Identification of Different Land Use Classes Affecting Traffic Flow}

There is a close association of land use and traffic congestion (Indian Road Congress, 1990). In research investigations related to urban system, the quantifying approach merely is not adequate. Formulation of policies and planning for the functioning of urban system requires knowledge acquired from direct observations (Lwin et al., 2012). Therefore, in the present research investigation, rigorous field survey was done to identify different existing main land use classes i.e. Commercial, Residential, Industries, Urban services and sub-classes i.e. Shopping Centre, General Business, Neighborhood Commercial, Mixed Commercial (Commercial), Single Family Housing, Low Density Infill, Low Density Redevelopment, Apartments, Single Family Rural Housing (Residential), Institutional Services, Health Services, Low Industrial Zones, High Industrial Zones (Industries), Urban Service Zones, Urban Utility Zones, Urban Facility Zones (Urban services) that can influence flow of traffic. Further, different physical characteristics of traffic flow, i.e. free flow time, total travel time, average speed, stopped time were collected in the field using Moving Observer Technique (Taylor, 1992). Different land use classes and subclasses that can potentially affect the flow of traffic in the study area as discussed above are shown in the Fig. 2. The methodology (Fig. 3) employed in the present research investigation comprises three different parts. The first part comprises discussion on the quantification of the heterogeneity of land use on the basis of weights computed from Analytic Hierarchy Process (AHP) and knowledge based weights. The second part is comprised of computation of the congestion index value (Taylor, 1992) of different routes on the basis of free flow time and total travel time. The third and last part of the methodology provides discussion on the relationship between heterogeneity index and congestion index value.

\subsection{Determination of Importance Value (Priority Weight) of Different Criteria}

The main land use classes and sub classes as discussed in the section 2.2 were chosen as the main criteria and sub criteria respectively for the present research investigation. It is obvious that different land use classes would have varying degree of influence on the traffic flow conditions. Impact of a certain land use class on the flow of traffic depends upon its structural and functional characteristics. Hence it becomes imperative to rate the relative impact of different land use classes in influencing the traffic flow in different routes of the city. In the present research investigation, the Analytical Hierarchical Process technique was used to rate the relative importance of different land use classes, i.e. Commercial $\left(W_{1}\right)$, Residential $\left(W_{2}\right)$, Industries $\left(W_{3}\right)$, Urban services $\left(\mathrm{W}_{4}\right)$ and their various subclasses, i.e. Shopping centre $\left(W_{11}\right)$, General business $\left(W_{12}\right)$, Neighborhood commercial $\left(\mathrm{W}_{13}\right)$, Mixed commercial $\left(\mathrm{W}_{14}\right)$ pertaining to Commercial $\left(\mathrm{W}_{1}\right)$; Single family housing $\left(W_{21}\right)$, Low density infill $\left(W_{22}\right)$, Low density redevelopment $\left(\mathrm{W}_{23}\right)$, Apartments $\left(\mathrm{W}_{24}\right)$, Single family rural housing $\left(\mathrm{W}_{25}\right)$ under Residential $\left(\mathrm{W}_{2}\right)$; Institutional services $\left(\mathrm{W}_{31}\right)$, Health services $\left(\mathrm{W}_{32}\right)$, Low industrial zones $\left(\mathrm{W}_{33}\right)$, High industrial zones $\left(\mathrm{W}_{34}\right)$ under Industries $\left(\mathrm{W}_{3}\right)$; and Urban service zones $\left(W_{41}\right)$, Urban utility zones $\left(W_{42}\right)$, Urban facility zones $\left(W_{43}\right)$ under the Urban services $\left(W_{4}\right)$ in influencing the flow of traffic in the entire study area in 
the scale of $\{0,1\}$. The pair wise comparison (Priority weight/Importance value of the matrix of different criteria and sub criteria various main and sub criteria for the study is presented in the Table 1, 2, 3, 4 and 5 area), respectively.

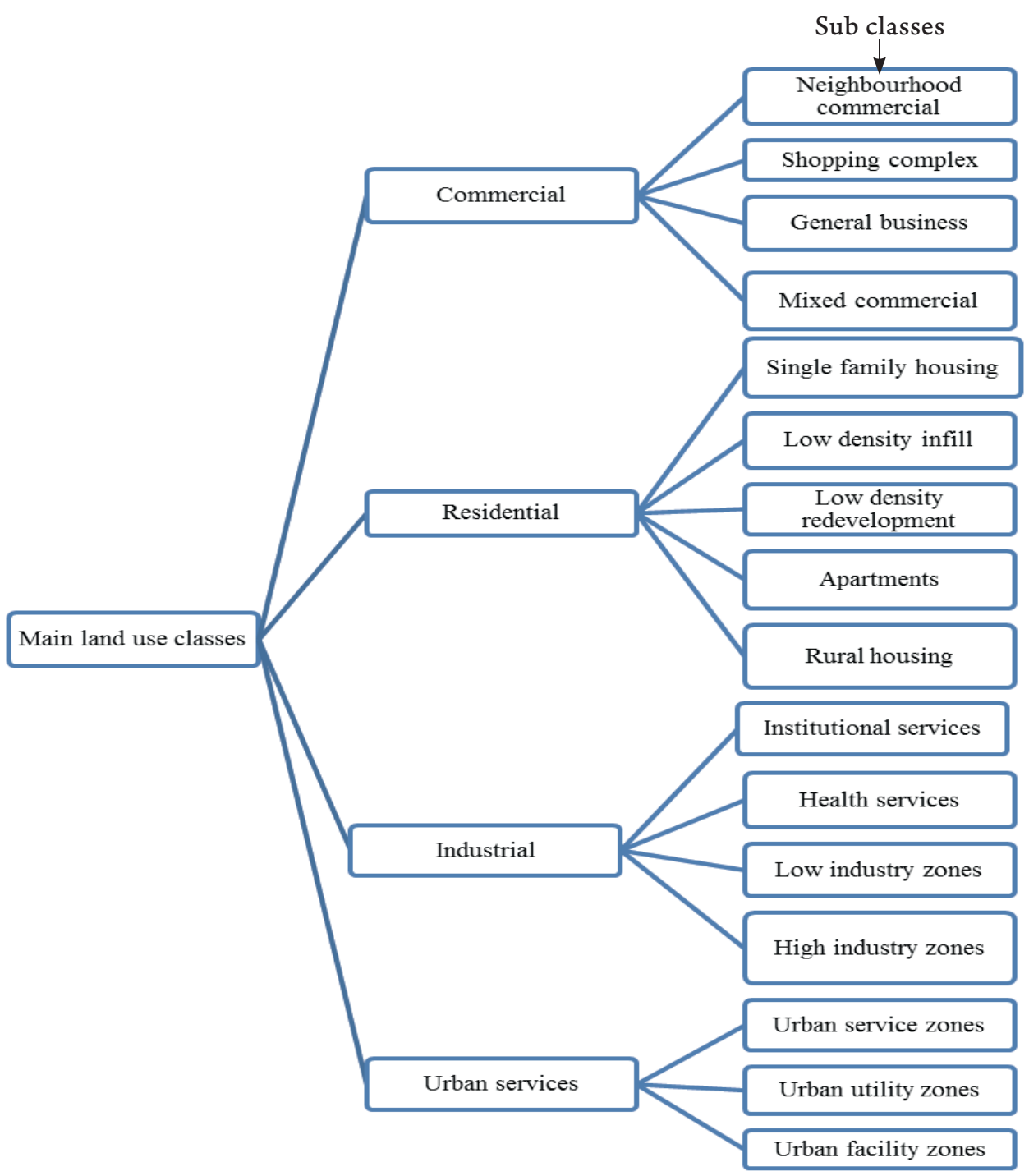

Fig. 2.

Dendrogram Showing the Various Main Land Use Classes and their Sub Classes 


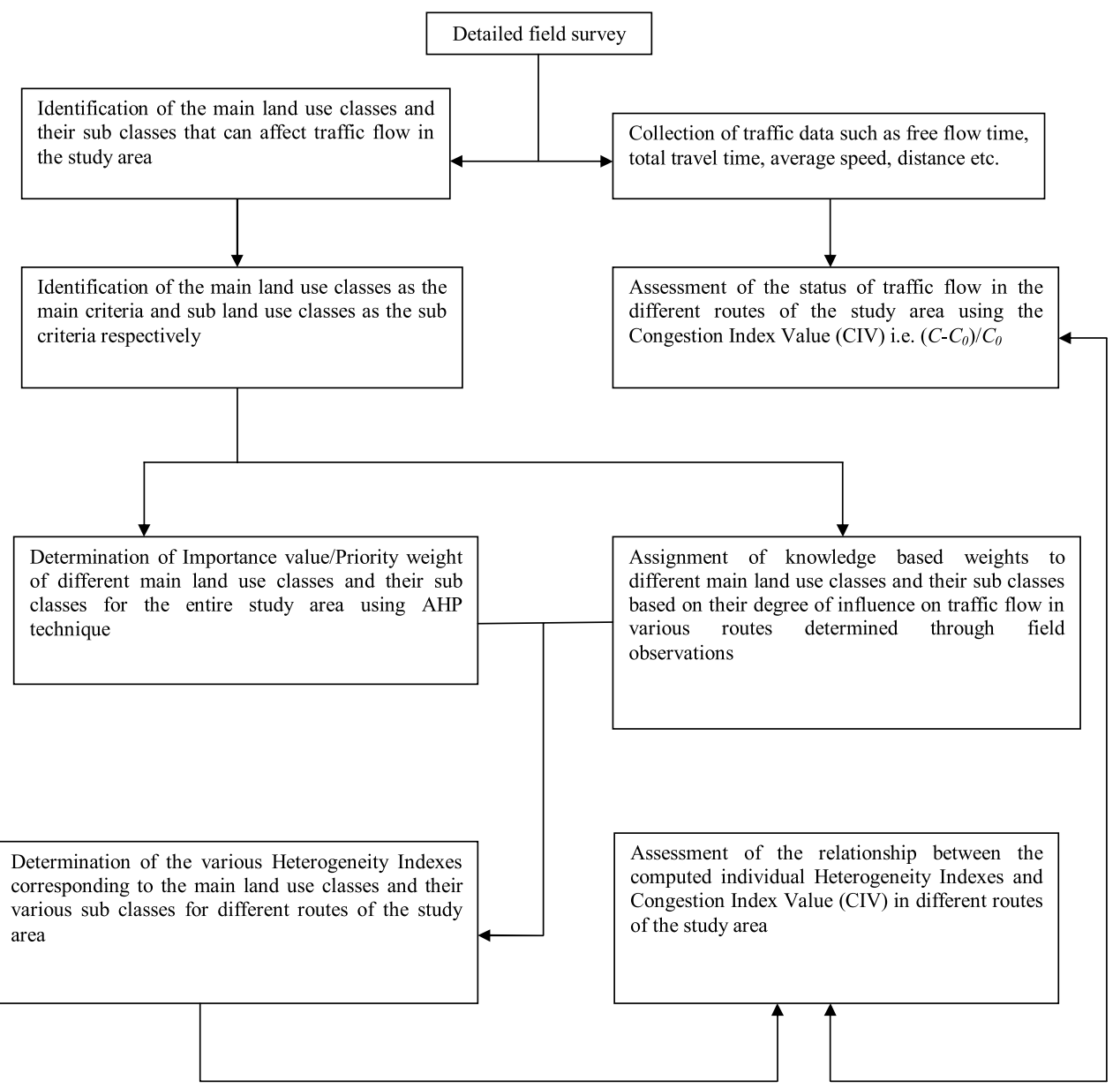

Fig. 3.

Methodology Flow Chart

\section{Table 1}

Pair Wise Comparison Matrix for the Main Land Use Classes

\begin{tabular}{|c|c|c|c|c|c|c|c|c|}
\hline & C & I & U & R & PR (Priority Weight) & $\lambda_{\max }$ & $\begin{array}{c}\text { CI (Consistency } \\
\text { Index) }\end{array}$ & $\begin{array}{c}\text { CR (Consistency } \\
\text { Ratio) }\end{array}$ \\
\hline C & 1 & 3 & 5 & 7 & 0.55 & & & \multirow{2}{*}{4.16} \\
I & 0.33 & 1 & 3 & 5 & 0.26 & 0.05 & 0.06 \\
\hline U & 0.20 & 0.33 & 1 & 5 & 0.14 & & & \\
\hline R & 0.14 & 0.20 & 0.20 & 1 & 0.05 & & \\
\hline
\end{tabular}

Note: C: Commercial, I: Industrial, U: Urban services, R: Residential, $\lambda_{\max }$ : Maximum Eigen value 
Table 2

Pair Wise Comparison Matrix for the Various Sub Classes of the Main Land Use Class Residential

\begin{tabular}{|c|c|c|c|c|c|c|c|c|c|}
\hline & SFH & LDI & AP & LDR & RUH & PR ( Priority Weight) & $\lambda_{\max }$ & $\begin{array}{c}\text { CI (Consistency } \\
\text { Index) }\end{array}$ & $\begin{array}{c}\text { CR (Consistency } \\
\text { Ratio) }\end{array}$ \\
\hline SFH & 1 & 0.50 & 0.33 & 0.25 & 1 & 0.09 & \multirow{5}{*}{5.12} & \multirow{5}{*}{0.03} & \multirow{5}{*}{0.03} \\
\hline LDI & 2 & 1 & 0.50 & 0.33 & 2 & 0.16 & & & \\
\hline $\mathrm{AP}$ & 3 & 2 & 1 & 0.50 & 2 & 0.24 & & & \\
\hline LDR & 4 & 3 & 2 & 1 & 4 & 0.42 & & & \\
\hline$\overline{\text { RUH }}$ & 1 & 0.50 & 0.50 & 0.25 & 1 & 0.10 & & & \\
\hline
\end{tabular}

Note: SFH: Single Family Housing, LDI: Low Density Infill, AP: Apartments, LDR: Low Density

Redevelopment, $R U H$ : Rural Housing, $\lambda_{\text {max }}:$ Maximum Eigen value

Table 3

Pair Wise Comparison Matrix for the Various Sub Classes of the Main Land Use Class Commercial

\begin{tabular}{|c|c|c|c|c|c|c|c|c|}
\hline & NCZ & SC & GB & MC & PR (Priority Weight) & $\lambda_{\max }$ & $\begin{array}{c}\text { CI (Consistency } \\
\text { Index) }\end{array}$ & $\begin{array}{c}\text { CR (Consistency } \\
\text { Ratio) }\end{array}$ \\
\hline NCZ & 1 & 0.25 & 0.33 & 0.14 & 0.06 & & & \\
SC & 4 & 1 & 2 & 0.25 & 0.21 & \multirow{2}{*}{4.09} & 0.03 & 0.03 \\
\hline GB & 3 & 0.50 & 1 & 0.20 & 0.13 & & \\
\hline MC & 7 & 4 & 5 & 1 & 0.60 & & & \\
\hline
\end{tabular}

Note: NCZ: Neighborhood Commercial Zone, SC: Shopping Centers, GB: General Business, MC:

Mixed Commercial, $\lambda_{\max }:$ Maximum Eigen value

Table 4

Pair Wise Comparison Matrix for the Various Sub Classes of Use Class the Main Land Industrial

\begin{tabular}{|c|c|c|c|c|c|c|c|c|}
\hline & IS & HS & LIZ & HIZ & PR (Priority Weight) & $\lambda_{\max }$ & $\begin{array}{c}\text { CI (Consistency } \\
\text { Index) }\end{array}$ & $\begin{array}{c}\text { CR (Consistency } \\
\text { Ratio) }\end{array}$ \\
\hline IS & 1 & 3 & 4 & 5 & 0.52 & & & \\
\cline { 1 - 5 } HS & 0.33 & 1 & 3 & 4 & 0.27 & \multirow{2}{*}{4.17} & 0.06 & 0.06 \\
\hline LIZ & 0.25 & 0.33 & 1 & 3 & 0.14 & & \\
\hline HIZ & 0.20 & 0.25 & 0.33 & 1 & 0.07 & & & \\
\hline
\end{tabular}

Note: IS: Institutional Services, HS: Health Services, LIZ: Low Industrial Zones, HIZ: High Industrial Zones, $\lambda_{\text {max }}:$ Maximum Eigen value

\section{Table 5}

Pair Wise Comparison Matrix for the Various Sub Classes of the Main Land Use Class Urban Services

\begin{tabular}{|c|c|c|c|c|c|c|c|}
\hline & USZ & UUZ & UFZ & PR (Priority Weight) & $\lambda_{\max }$ & CI (Consistency Index) & CR (Consistency Ratio) \\
\hline USZ & 1 & 4 & 7 & 0.70 & & & \multirow{2}{*}{0.04} \\
UUZ & 0.25 & 1 & 3 & 0.21 & 3.07 & 0.06 & \\
\hline UFZ & 0.14 & 0.33 & 1 & 0.09 & & & \\
\hline
\end{tabular}

Note: USZ: Urban Service Zones, UUZ: Urban Utility Zones, UFZ: Urban Facility Zones, גmax: Maximum Eigen value 


\subsubsection{Analytic Hierarchy Process (AHP)}

The Analytic Hierarchy Process (AHP) is a decision making technique which was originally developed by Thomas L. Saaty (1980). In this technique, paired comparisons are used to derive ratio scales. In pair wise comparisons, judgment is done on the basis of a common scale. The input can be obtained from actual measurement or from subjective opinion. The advantage of this approach is that a small amount of inconsistency can be considered in the process of decision making. The ratio scales can be computed with the help of principal Eigen vectors and the consistency index is derived from the principal Eigen value.

\subsubsection{Construction and Computation of Priority Vectors in Comparison Matrix}

In a comparison matrix, if there are $n$ parameters then a comparison matrix of $n$ by $n$ order need to be made. In the matrix, 1 will be assigned to the diagonal elements. If a parameter in $i_{t h}$ row is $m$ times more important than a parameter of $j_{\text {th }}$ column then value of the element $a_{i j}$ would be $m$ and value of the element $a_{j i}$ would be $1 / m$. Having constructed comparison matrix, the priority vectors, i.e. normalized Eigen vectors are computed for different parameters. Since it is a normalized Eigen vector, the sum of all normalized Eigen vectors must be equal to 1 otherwise the results lead to erroneous scenario.

The process of computing priority vectors and checking its consistency is explained as follows:

- Addition of column elements of each column of the pair wise comparison matrix.

- Dividing each element of the pair wise comparison matrix by the respective sum of their column elements.

- Averaging of row elements across the rows of pair wise comparison matrix to determine the priority vector or normalized Eigen vector $(\lambda)$ (the sum of priority vectors must not exceed one since priority vectors are normalized).

- Principal Eigen value $\left(\lambda_{\max }\right)$ is obtained by the summation of products between each element of priority vector and the sum of respective column elements.

- After computing the principal Eigen value, the consistency index $(\mathrm{CI})$ is computed using the formulae $\left(\lambda_{\max }-n\right)$ / $(n-1)$ where $n$ is the order of comparison matrix.

- Finally, consistency ratio (CR) is determined using the formulae CI/ $\mathrm{RI}$ where RI is random consistency index (the consistency ratio should not exceed 0.1; if it exceeds, the pair wise comparisons need alteration).

\subsection{Assignment of Knowledge Based Weighting to Different Criteria and Sub Criteria}

Determination of Importance value (Priority weight) of different main criteria (main land use classes) and sub criteria (sub classes) for the entire study area using Analytical Hierarchical Process technique (AHP) provides the relative importance of a land use class with respect to the other existing land use classes present in the entire study area. However, it is not necessary that the functional activities of a specific land use class are equal in all the routes present in the study area. Therefore, it is desired to normalize the differences in the functional activities of the respective land use classes across all the routes present in the study area. Practically, it is difficult to quantify the 
influence of the presence of different criteria and sub criteria in different routes of the study area. Therefore, based on the detailed field survey and observations knowledge based weighting was provided to each main criteria and their corresponding sub criteria in the scale of $\{0,1\}$ in order to assess the influence of the presence of the various main criteria and their sub-criteria in different routes. The knowledge based weighting of the various main criteria and their sub-criteria for different routes is presented in Table 6.

\section{Table 6}

Knowledge Based Weighting Assigned to Different Sub Classes in the Various Routes Based on Field Observation

\begin{tabular}{|c|c|c|c|c|c|c|c|c|c|c|c|c|c|c|c|c|}
\hline Route ID & SFH & LDI & LDR & AP & RUH & $\mathrm{NCZ}$ & SC & GB & $\mathbf{C M}$ & IS & HS & LIZ & HIZ & USZ & $\mathbf{U U Z}$ & UFZ \\
\hline 1 & 0.30 & 0.20 & 0.10 & 0.10 & 0.10 & 0.20 & 0.00 & 0.00 & 0.00 & 0.00 & 0.00 & 0.00 & 0.00 & 0.10 & 0.10 & 0.00 \\
\hline 2 & 0.40 & 0.40 & 0.30 & 0.20 & 0.10 & 0.20 & 0.10 & 0.20 & 0.10 & 0.30 & 0.20 & 0.00 & 0.00 & 0.20 & 0.11 & 0.00 \\
\hline 3 & 0.20 & 0.20 & 0.20 & 0.10 & 0.10 & 0.20 & 0.20 & 0.40 & 0.30 & 0.10 & 0.00 & 0.00 & 0.00 & 0.10 & 0.10 & 0.00 \\
\hline 4 & 0.30 & 0.30 & 0.40 & 0.10 & 0.20 & 0.50 & 0.50 & 0.40 & 0.80 & 0.30 & 0.30 & 0.10 & 0.00 & 0.30 & 0.40 & 0.00 \\
\hline 5 & 0.10 & 0.20 & 0.30 & 0.10 & 0.10 & 0.30 & 0.10 & 0.10 & 0.50 & 0.20 & 0.00 & 0.10 & 0.00 & 0.30 & 0.20 & 0.00 \\
\hline 6 & 0.30 & 0.40 & 0.10 & 0.10 & 0.10 & 0.10 & 0.00 & 0.00 & 0.20 & 0.00 & 0.00 & 0.00 & 0.00 & 0.50 & 0.30 & 0.10 \\
\hline 7 & 0.50 & 0.60 & 0.50 & 0.50 & 0.10 & 0.40 & 0.30 & 0.50 & 0.50 & 0.50 & 0.20 & 0.10 & 0.00 & 0.30 & 0.20 & 0.00 \\
\hline 8 & 0.40 & 0.50 & 0.30 & 0.30 & 0.10 & 0.20 & 0.20 & 0.10 & 0.10 & 0.30 & 0.00 & 0.10 & 0.00 & 0.20 & 0.10 & 0.00 \\
\hline 9 & 0.10 & 0.10 & 0.10 & 0.00 & 0.10 & 0.30 & 0.00 & 0.00 & 0.10 & 0.00 & 0.00 & 0.10 & 0.00 & 0.10 & 0.10 & 0.00 \\
\hline 10 & 0.10 & 0.10 & 0.10 & 0.20 & 0.10 & 0.10 & 0.10 & 0.00 & 0.00 & 0.00 & 0.00 & 0.10 & 0.00 & 0.10 & 0.10 & 0.00 \\
\hline 11 & 0.20 & 0.20 & 0.30 & 0.20 & 0.10 & 0.40 & 0.10 & 0.10 & 0.10 & 0.20 & 0.10 & 0.10 & 0.00 & 0.30 & 0.10 & 0.10 \\
\hline 12 & 0.40 & 0.50 & 0.20 & 0.20 & 0.10 & 0.40 & 0.10 & 0.20 & 0.10 & 0.30 & 0.50 & 0.10 & 0.00 & 0.20 & 0.30 & 0.00 \\
\hline 13 & 0.40 & 0.50 & 0.60 & 0.70 & 0.10 & 0.40 & 0.10 & 0.10 & 0.20 & 0.10 & 0.50 & 0.10 & 0.00 & 0.40 & 0.30 & 0.00 \\
\hline 14 & 0.00 & 0.00 & 0.00 & 0.00 & 0.00 & 0.00 & 0.00 & 0.10 & 0.00 & 0.00 & 0.00 & 0.00 & 0.00 & 0.00 & 0.00 & 0.00 \\
\hline 15 & 0.70 & 0.60 & 0.20 & 0.10 & 0.30 & 0.50 & 0.10 & 0.30 & 0.60 & 0.10 & 0.40 & 0.10 & 0.00 & 0.20 & 0.20 & 0.20 \\
\hline 16 & 0.50 & 0.60 & 0.30 & 0.30 & 0.10 & 0.50 & 0.20 & 0.10 & 0.30 & 0.30 & 0.20 & 0.10 & 0.00 & 0.30 & 0.40 & 0.00 \\
\hline 17 & 0.50 & 0.60 & 0.40 & 0.20 & 0.10 & 0.50 & 0.10 & 0.00 & 0.10 & 0.10 & 0.10 & 0.10 & 0.00 & 0.30 & 0.20 & 0.10 \\
\hline 18 & 0.10 & 0.20 & 0.10 & 0.10 & 0.10 & 0.20 & 0.00 & 0.00 & 0.10 & 0.10 & 0.10 & 0.10 & 0.00 & 0.20 & 0.20 & 0.00 \\
\hline 19 & 0.40 & 0.40 & 0.50 & 0.40 & 0.10 & 0.70 & 0.30 & 0.20 & 0.30 & 0.10 & 0.40 & 0.10 & 0.00 & 0.20 & 0.40 & 0.00 \\
\hline 20 & 0.60 & 0.60 & 0.30 & 0.10 & 0.30 & 0.70 & 0.10 & 0.10 & 0.70 & 0.40 & 0.30 & 0.40 & 0.00 & 0.20 & 0.30 & 0.00 \\
\hline 21 & 0.50 & 0.30 & 0.30 & 0.10 & 0.20 & 0.40 & 0.10 & 0.10 & 0.20 & 0.30 & 0.10 & 0.10 & 0.00 & 0.10 & 0.20 & 0.00 \\
\hline 22 & 0.50 & 0.10 & 0.10 & 0.10 & 0.40 & 0.60 & 0.10 & 0.10 & 0.20 & 0.10 & 0.10 & 0.10 & 0.00 & 0.10 & 0.40 & 0.00 \\
\hline 23 & 0.60 & 0.70 & 0.30 & 0.10 & 0.40 & 0.70 & 0.50 & 0.50 & 0.80 & 0.40 & 0.30 & 0.20 & 0.00 & 0.40 & 0.50 & 0.00 \\
\hline 24 & 0.40 & 0.30 & 0.40 & 0.30 & 0.20 & 0.40 & 0.10 & 0.10 & 0.20 & 0.20 & 0.10 & 0.10 & 0.00 & 0.10 & 0.20 & 0.00 \\
\hline
\end{tabular}




\subsection{Quantification of Heterogeneity in the Land Use Pattern along the Roads}

There are four different main land use classes, i.e. Commercial, Residential, Industries, Urban services and sub classes, i.e. Shopping centre, General business, Neighborhood commercial, Mixed commercial (Commercial), Single family housing, Low density infill, Low density redevelopment, Apartments, Single family rural housing (Residential), Institutional services, Health services, Low industrial zones, High industrial

Cumulative Heterogeneity Index (CUHI):

Commercial Heterogeneity Index (CHI):

Residential Heterogeneity Index (RHI):

Industrial Heterogeneity Index (IHI):

Urban Services Heterogeneity Index (USHI):

\subsection{Assessment of Relationship between the Land Use Pattern and Traffic Flow}

All the five heterogeneity indexes were computed for the different routes of the study area and the results are presented in Table 7. Since the significance of the different heterogeneity indexes lies in their ability to indicate the occurrence of probable relationship of land use pattern and traffic flow, the values of the different heterogeneity indexes can be used as indicative variable for the assessment of magnitude of traffic flow in different routes of the study area. The status of congestion zones (Industries), Urban service zones, Urban utility zones, Urban facility zones (Urban services) that exist along the various roads. In the present research investigation, the heterogeneity in the aforementioned main land use classes were quantified in terms of Commercial Heterogeneity Index (CHI), Residential Heterogeneity Index (RHI), Industrial Heterogeneity Index (IHI), Urban Services Heterogeneity Index (UHI), and Cumulative Heterogeneity Index (CUHI). The different heterogeneity Indexes were computed as follows (Eqs. (1-5)):

$$
\begin{aligned}
& \left(W_{1}{ }^{*} K_{1}+W_{2}{ }^{*} K_{2}+W_{3}{ }^{*} K_{3}+W_{4}{ }^{*} K_{4}\right) \\
& \left(W_{11}{ }^{*} K_{11}+W_{12}{ }^{*} K_{12}+W_{13}{ }^{*} K_{13}+W_{14}{ }^{*} K_{14}\right) \\
& \left(W_{21}{ }^{*} K_{21}+W_{22}{ }^{*} K_{22}+W_{23}{ }^{*} K_{23}+W_{24}{ }^{*} K_{24}+W_{25}{ }^{*} K_{25}\right) \\
& \left(W_{31}{ }^{*} K_{31}+W_{32}{ }^{*} K_{32}+W_{33}{ }^{*} K_{33}+W_{34}{ }^{*} K_{34}\right) \\
& \left(W_{41}{ }^{*} K_{41}+W_{42}{ }^{*} K_{42}+W_{43}{ }^{*} K_{43}\right)
\end{aligned}
$$

in different routes was determined on the basis of congestion index value calculated from the formula $\left(C-C_{0}\right) / C_{0}$ (Taylor, 1992) where $C$ is total travel time and $C_{0}$ is free flow time. According to Taylor (1992), if the value of congestion index value is greater than 2 , it corresponds to congested conditions. The congestion index value near 0 represents low level of congestion. Having computed heterogeneity indexes and congestion index value (CIV) for different routes, the relationship between the values of different heterogeneity indexes and congestion status in different routes was determined. 


\section{Table 7}

Values of Different Heterogeneity Indexes and Congestion Index Value in Various Routes

\begin{tabular}{|c|c|c|c|c|c|c|c|}
\hline Route ID & Routes & CUHI & RHI & CHI & IHI & USHI & $\mathrm{CIV}=\left(\mathrm{C}-\mathrm{C}_{0}\right) / \mathrm{C}_{0}$ \\
\hline 1 & Birsa Chowk to Hinoo chowk & 0.16 & 0.14 & 0.01 & 0 & 0.09 & 0.85 \\
\hline 2 & Hinoo Chowk to Rajendra chowk & 0.19 & 0.28 & 0.12 & 0.21 & 0.16 & 0.92 \\
\hline 3 & Rajendra chowk to Sujata Chowk & 0.28 & 0.17 & 0.29 & 0.05 & 0.09 & 0.67 \\
\hline 4 & Sujata Chowk to Firayalal Chowk & 0.58 & 0.29 & 0.67 & 0.25 & 0.29 & 2.29 \\
\hline 5 & Firayalal Chowk to Saheed chowk & 0.44 & 0.20 & 0.35 & 0.12 & 0.25 & 2.22 \\
\hline 6 & Saheed chowk to Kutchary chowk & 0.28 & 0.17 & 0.13 & 0 & 0.42 & 0.59 \\
\hline 7 & Kutchary chowk to Lalpur Chowk & 0.45 & 0.48 & 0.45 & 0.33 & 0.25 & 1.45 \\
\hline 8 & Lalpur Chowk to Dangratoli Chowk & 0.27 & 0.32 & 0.13 & 0.17 & 0.16 & 0.63 \\
\hline 9 & Dangratoli Chowk to Kantatoli Chowk & 0.15 & 0.08 & 0.08 & 0.01 & 0.09 & 1.39 \\
\hline 10 & Kantatoli Chowk to Kokar Chowk & 0.16 & 0.13 & 0.03 & 0.01 & 0.09 & 0.89 \\
\hline 11 & Kokar Chowk to Booty More & 0.28 & 0.23 & 0.12 & 0.15 & 0.24 & 0.29 \\
\hline 12 & Booty More to Bariyatu & 0.24 & 0.26 & 0.13 & 0.31 & 0.20 & 0.11 \\
\hline 13 & Bariyatu to Karam Toli & 0.29 & 0.55 & 0.18 & 0.20 & 0.34 & 0.17 \\
\hline 14 & Karam Toli to Sainik Theatre & 0.10 & 0 & 0.01 & 0 & 0 & 0.21 \\
\hline 15 & Sainik Theatre to Ratu Chowk & 0.35 & 0.30 & 0.45 & 0.17 & 0.20 & 0.78 \\
\hline 16 & Ratu Chowk to Sahajanand Chowk & 0.34 & 0.35 & 0.27 & 0.22 & 0.29 & 0.90 \\
\hline 17 & Sahajanand Chowk to Argora Chowk & 0.15 & 0.37 & 0.11 & 0.09 & 0.26 & 0.16 \\
\hline 18 & Argora Chowk to Birsa Chowk & 0.11 & 0.12 & 0.07 & 0.09 & 0.18 & 0.15 \\
\hline 19 & Firayalal Chowk to Lalpur Chowk & 0.46 & 0.42 & 0.31 & 0.17 & 0.22 & 1.50 \\
\hline 20 & Lalpur Chowk to Kokar Chowk & 0.42 & 0.33 & 0.50 & 0.35 & 0.20 & 1.21 \\
\hline 21 & Sujata Chowk to Bahoo Bazaar & 0.22 & 0.26 & 0.18 & 0.20 & 0.11 & 1.07 \\
\hline 22 & Bahoo Bazaar to Kantatoli Chowk & 0.30 & 0.17 & 0.19 & 0.09 & 0.15 & 1.16 \\
\hline 23 & Ratu Chowk to Piska More & 0.66 & 0.36 & 0.69 & 0.32 & 0.39 & 2.63 \\
\hline 24 & Piska More to Pandra & 0.34 & 0.34 & 0.18 & 0.15 & 0.11 & 1.47 \\
\hline
\end{tabular}

\section{Results and Discussion}

The present research investigation comprises two major parts: first, development of heterogeneity index to determine the heterogeneity in the distribution of the individual main land use classes and their corresponding sub classes along the various road segments and second, determination of relationship of the heterogeneity index corresponding to the different main land use classes with the traffic congestion. The formulation of proposed heterogeneity index presented is a novel technique whereas the traffic congestion has been determined using the traditional Congestion Index Value (CIV). The following sections describe the results and discussions of the various tasks performed to achieve the desired goals. 


\subsection{Results of Pair Wise Comparison Matrix for the Main Criteria and Sub- Criteria}

As discussed in the section 2.3, four significantly dominant land use classes were considered as the main criteria and a number of sub-classes pertaining to each main class were considered as sub criteria respectively. AHP technique was employed to determine the priority or the importance weight of the various main criteria and sub-criteria. The pair-wise matrix for the four main criteria, i.e. the main land use classes is presented in Table 1 whereas the pair-wise matrix for the different sub-classes pertaining to the four individual main land use classes such as Residential, Commercial, Industrial services and Urban services are shown in Tables 2, 3, 4 and 5, respectively. From the examination of Table 1 , it is clearly evident that the priority weight of the main land use class Commercial is highest (0.55) among the four main land use classes and is also considerably larger than the priority weight of the other three main land use classes. Therefore, among the different main land use classes, Commercial class possesses greatest importance in influencing traffic flow than the other existing land use classes present in the study area followed in decreasing order by Industrial, Urban Services and Residential land use class respectively. The priority weight of Residential class is extremely low (0.05) indicating that it has significantly no influence on the traffic congestion. These observations are also corroborated during the field survey carried out in the study area. Among the four sub classes of the Commercial land use class, i.e. Neighborhood Commercial Zone (NCZ), Shopping Centers (SC), General Business (GB) and Mixed Commercial (MC), the last one is associated with the highest priority weight of 0.60 and is therefore, considered as the most significant class in influencing the traffic flow congestion (Table 3 ). This observation is also ascertained during the field survey and is attributed both to their heterogeneous occurrence along the road segments and also, to their multi-utility services to the consumers' community. In the remaining three main land use classes, the subclass Low Density Redevelopment (LDR) of the main class Residential is more significant in affecting traffic flow in the study area with priority weight 0.42 and the least significant is Single Family Housing (SFH) (Table 2). From the examination of Table 4 and Table 5 respectively, it can be inferred that Institutional Services under the main class Industrial Services and Urban Service Zones under the main class Urban Services can have greater impact in influencing the flow of traffic in different routes of the city whereas the influence of High Industrial Zones and Public Facility Zones is almost nil.

\subsection{Influence of Individual Land Use Classes on the Traffic Flow in Different Routes}

The relative importance of the various land use classes in influencing traffic flow determined through AHP technique has been discussed in section 3.1. It is obvious that there will be significant variation of the heterogeneity of the distribution pattern of the various land use classes in the different road segments as a result of which the magnitude of influence of the individual land use classes on the traffic flow would vary across different road segments. In the present research, we assigned knowledge based weights to the different sub classes of the individual main classes based on their relative magnitude of influence on 
the traffic flow in the different routes on the basis of detailed field survey (Table 6). The knowledge based weights were assigned in the scale of $\{0,1\}$ in which a sub class assigned with a weight approaching 1 would indicate its greater degree of influence on the traffic flow in a particular road segment while weights nearing zero would indicate the occurrence of significantly very less influence of the class on the traffic flow in the concerned routes. In some of the road segments, one or more number of sub classes may not be present due to which the heterogeneity index corresponding to such sub classes have been assigned zero values.

\subsection{Assessment of Traffic Congestion in Different Routes of the Study Area}

The status of traffic congestion in different routes of the study area is presented in Table 7. Examination of Table 7 indicates that Route nos. 4, 5 and 23 are congested since their Congestion Index Value (CIV) is greater than 2, i.e. 2.29, 2.22 and 2.63, respectively. On the other hand, there are routes (i.e. Route nos. 7, 9 and 19 with CIV $1.45,1.39$ and 1.50 , respectively) in which the Congestion Index Value is nearing to 2 representing congested conditions whereas in Route nos. 11, 12, 13, 14, 17 and 18, the Congestion Index Value (CIV) is very close to 0 , i.e. $0.29,0.11,0.17,0.21,0.16$ and 0.15 respectively representing smooth flow of traffic.

\subsection{Relationship between Land Use Heterogeneity and Congestion Index Value in Different Routes}

The heterogeneity in the distribution of land use along different routes of the study area was computed using the five different heterogeneity indices, i.e.
Commercial Heterogeneity Index (CHI), Residential Heterogeneity Index (RHI), Industrial Heterogeneity Index (IHI), Urban Services Heterogeneity Index (USHI) and Cumulative Heterogeneity Index (CUHI). The values of five different heterogeneity indices for the different routes are presented in Table 7 . The highest value of the Cumulative Heterogeneity Index (CUHI) (0.66) is associated with route no. 23. Among the four heterogeneity indexes developed corresponding to the four main land use classes, i.e. commercial, industrial, residential and urban services respectively, the Commercial Heterogeneity Index (CHI) is found to be the highest with a value of 0.69 (route no. 23) followed in decreasing order by the Residential Heterogeneity Index (RHI) with a value of 0.55 associated with route no. 13, Urban Services Heterogeneity Index (USHI) (0.42 with route no. 6$)$ and Industrial Heterogeneity Index (IHI) having the least value of 0.35 associated with route no. 20, respectively. Comparative analysis between the highest values of the different heterogeneity indexes and the corresponding Congestion Index Values (CIV) provides the following inferences. The highest values of both CHI (0.69) and CIV (2.63) are associated with the same route i.e. route no. 23 indicating the occurrence of linear relationship between these two parameters. On the other hand, the highest value of $\mathrm{RHI}$, i.e. 0.55 observed in route no. 13 is associated with one of the lowest values of CIV (0.17) that indicates significantly opposite relationship between these two parameters.

\subsection{Correlation between Heterogeneity Index and Traffic Congestion (CIV)}

The coefficient of correlation between the individual heterogeneity indexes and 
Congestion Index Values for the different routes of the study area was determined in order to find out the land use classes that cause maximum and minimum influence on the traffic congestion in the study area, respectively. It was found that there occurs highest correlation between the Cumulative Heterogeneity Index (CUHI) and Congestion Index Value (CIV), i.e. 0.79 in the study area, which is followed closely by the correlation between the Commercial Heterogeneity Index (CHI) and Congestion Index Value (CIV) with correlation coefficient value of 0.72 . On the other hand, the least correlation coefficient occurs between the Residential Heterogeneity Index (RHI) and CIV with a value of 0.16 . The correlation coefficient of the Industrial Heterogeneity Index (IHI) and Urban Services Heterogeneity Index (USHI) with CIV are found to be 0.33 and 0.23 , respectively. These observations clearly indicate the occurrence of significantly strong relationship of $\mathrm{CHI}$ with $\mathrm{CIV}$ while the residential heterogeneity is found to have the least influence in causing traffic congestion in the study area. The other two heterogeneity indexes: Industrial Heterogeneity Index (IHI) and Urban Services Heterogeneity Index (USHI) are also found to have very less influence on the traffic flow in the study area. These inferences are also corroborated during the field observations.

\section{Conclusions}

Uncontrolled urban expansion is now a common phenomenon in the developing countries. The uncontrolled urban expansion not just exerts pressure on the peripheral areas of a city but also it has significant impact on the interior landscape of the city. One of the most harmful effects of urbanization is the rapid increase in the traffic congestion in urban regions, an issue which has now emerged as a serious threat to urban sustainability and hence, poses a huge challenge to researchers, urban planners and policy makers to come up with remedial solutions.

The present research investigation was performed to assess the relationship between the land use distribution pattern and traffic congestion in the rapidly yet haphazardly expanding Ranchi city, capital of Jharkhand state, India. We have proposed a novel technique (index) termed as heterogeneity index in order to determine the distribution of land use pattern present in an area. Taking into consideration the main land use classes present in the study area, four such heterogeneity indexes were developed: Commercial Heterogeneity Index (CHI), Residential Heterogeneity Index (RHI), Industrial Heterogeneity Index (IHI) and Urban Services Heterogeneity Index (USHI) that were computed based on the heterogeneity in the distribution of the various land use sub classes present within each main land use class. In addition, a Cumulative Heterogeneity Index (CUHI) was also developed that is computed by considering the heterogeneity in the distribution of the four main land use classes. The five heterogeneity indexes were determined for each of the 24 major routes present in the study area. Analytical Hierarchical Processing (AHP) technique was employed to determine the relative importance of the different main land use classes and their sub classes in terms of their influence in causing traffic congestion. For each of the routes, the Congestion Index Value (CIV) was also determined. Pearsons' correlation coefficients were computed between the individual heterogeneity 
indexes and CIV for all the routes in order to determine the degree of influence of the various heterogeneity indexes on the traffic congestion. It was found that there occurs significantly positive relationship between each of the Cumulative and Commercial Heterogeneity Index with CIV while the Residential Heterogeneity Index was found to be least correlated with CIV. The other two heterogeneity indexes were also found to be poorly correlated with CIV. These observations are also corroborated during the field survey carried out in the study area. The results determined from the investigations performed in the present study demonstrate that the heterogeneity index that represents the heterogeneity in the distribution of the various main land use classes and their sub classes serves as a significantly potential indicator of the traffic congestion in an area. Moreover, such indices can also be used for effective town planning in order to alleviate traffic congestion in the various routes and in the entire city.

\section{Acknowledgements}

The authors express their sincere thanks to the Vice Chancellor of the Birla Institute of Technology, Mesra, and Ranchi, India for providing the necessary facilities to carry out the desired research in the Digital Image Processing and GIS laboratory of the Department of Remote Sensing, BIT Mesra. This research comprises a part of the $\mathrm{PhD}$ dissertation of Mr. Alok Bhushan Mukherjee under the supervision of Prof. Dr. A.P. Krishna and Prof. Dr. Nilanchal Patel.

\section{References}

Blanco, H.; Giuliano, G. 2011. Towards evidence-based sustainable communities. Report on survey of urban sustainability centers in U.S. universities. USC centre for sustainable cities.

Boamah, S.A. 2010. Spatial and temporal analyses of traffic flows in the city of Almelo: in search for a Microscopic Fundamental Diagram (MFD). Dissertation, the Netherlands: University of Twente, Enschede.

Chari, K.B.; Basawaraja, R.; Mise, S.R.; Chetti, S.B. 2011. Analysis of the impact of urban sprawl in altering the land-use, land-cover pattern of Raichur City, India, using geospatial technologies, Journal of Geographical Regional Planning, 4(8): 455-462.

Cheng, J. 2003. Modelling spatial and temporal urban growth. Ph.D. Thesis, the Netherlands: Utrecht University.

Geshkov, M.V. 2010. The Effect of Land-Use Controls on Urban Sprawl. Ph.D. Thesis, the University of South Florida.

Godescu, A.; Zurich, E. 2010. The efficient pedestrian flow hypothesis, European Journal of Scientific Research, 44(2): 220-227.

Hua, S.; Wang, J.; Zhu, Y. 2013. Cause analysis and countermeasures of Beijing city congestion, Procedia - Social and Behavioral Sciences. In Proceedings of the 13th COTA International Conference of Transportation Professionals (CICTP). DOI: http://dx.doi.org/10.1016/j. sbspro.2013.08.162, 96(6): 1426-1432.

Lee, W.P.; Osman, M.A.; Talib, A.Z.; Ismail, A.I.M. 2008. Dynamic traffic simulation for traffic congestion problem using an enhanced algorithm, World Academy of Science, Engineering and Technology, 2(9): 36-43. 
Li, H.; Wu, J. 2004. Use and misuse of landscape indices, Landscape Ecology. DOI: http://dx.doi.org/10.1023/ B:LAND.0000030441.15628.d6, 19(4): 389-399.

Li, Y.; Tsukaguchi, H. 2005. Relationships between network topology and pedestrian route choice behavior, Journal of Eastern Asia Society of Transportation Studies, 6(2005): 241-248.

Lindsey, C.R.; Verhoef, E.T. 2000. Traffic congestion and congestion pricing. Institute Discussion Paper, 101/3.

Lwin, K.K.; Yuji, M.; Chiaki, M. 2012. Quantitative versus qualitative geospatial data in spatial modelling and decision making, Journal of Geographic Information System. DOI: http://dx.doi.org/10.4236/jgis.2012.43028, 4(3): 237-241.

Narayanan, R.; Udayakumar, R.; Kumar, K.; Subbaraj, L. 2003.Quantification of congestion using Fuzzy Logic and Network Analysis using GIS, Map India Conference.

Ojima, R.; Hogan, D.J. 2009. Mobility, urban sprawl and environmental risks in Brazilian urban agglomerations: challenges for urban sustainability. Urban populationenvironment dynamics in the developing world: case studies and lessons learned. Paris: Committee for international cooperation in national research in demography (CICRED). 282-316.

Rahman, G.; Alam, D.; Islam, S. 2008. City growth with urban sprawl and problems of management, $44^{\text {th }}$ ISOCARP Congress.

Shen, L.; Kyllo, J.M.; Guo, X. 2013. An integrated model based on a hierarchical indices system for monitoring and evaluating urban sustainability, Sustainability. DOI: http://dx.doi.org/10.3390/su5020524, 5(2): 524-559.
Srinivasan, S. 2000. Linking land use and transportation: measuring the impact of neighborhood-scale spatial patterns on travel behavior, Dissertation, Harvard University.

Sudhira, H.S.; Ramachandra, T.V.; Jagadish, K.S. 2004. Urban sprawl: metrics, dynamics and modelling using GIS, International Journal of Applied Earth Observation and Geoinformation. DOI: http://dx.doi.org/10.1016/j. jag.2003.08.002, 5(1): 29-39.

The Indian Road Congress, New Delhi. 1990. Guidelines for capacity of urban roads in plan areas.

Taylor, M.A.P. 1992. Exploring the nature of urban traffic congestion: concepts, parameters, theories and models. In Proceedings of the 16th Conference of the Australian Road Research Board. 83-104.

Thuy, T.T. 2003. System dynamic applied to study the urban traffic Congestion of Hanoi. In Proceedings of the Eastern Asia Society for Transportation Studies. 1693-1697.

Williams, K. 2010. Sustainable cities: research and practice challenges, International Journal of Urban Sustainable Development, 1(1): 128-133.

Yang, Y.2010. Sustainable urban transformation driving forces, indicators and processes, M.Sc. Dissertation, BauhausUniversity Weimar, China.

Zavrl, M.S.; Zeren, M.T. 2010. Sustainability of urban infrastructures, Sustainability. DOI: http://dx.doi. org/10.3390/su2092950, 2(9): 2950-2964.

Zito, R.; D’Este, M.G.; Taylor, M.A.P. 1999. Using GPS to measure traffic system performance, Computer-Aided Civil and Infrastructure Engineering. DOI: http://dx.doi. org/10.1111/0885-9507.00146, 14(4): 255-265. 